\title{
NONLINEAR ANALYSIS OF HIGH Q RADIO FREQUENCY ENERGY HARVESTING NETWORKS
}

\author{
Christian Merz, Gerald Kupris
}

Deggendorf Institute of Technology, Faculty of Electrical Engineering, Media Technology and Computer Science

Abstract. The paper focuses on nonlinear analysis of high and low $Q$ RF energy harvesting circuits. The analysis is made mathematically and by large signal simulation via Keysight Advanced Design System. The mathematical analysis of the nonlinear harvesting circuits is done by using the Galerkin method and the simulations are performed using the harmonic balance method, which is a special version of the Galerkin method.

Keywords: Galerkin method, high Q impedance matching, nonlinear circuit analysis, radio frequency energy harvesting

\section{NIELINIOWA ANALIZA SIECI ZBIERAJĄCYCH ENERGIE W ZAKRESIE RADIOWYM O WYSOKIM WSPÓLCZYNNIKU DOBROCI Q}

Streszczenie. Artykut poświęcony jest nieliniowej analizie obwodów zbierających energię o wysokim $i$ niskim współczynniku dobroci Q, w zakresie częstotliwości radiowych. Z użyciem Keysight Advanced Design System wykonano analizę wielkosygnałową. Przeprowadzono również matematyczną analize nieliniowych obwodów zbierajacych energię z użyciem metody Galerkina oraz symulacje za pomoca metody balansu harmonicznego, która jest wersja metody Galerkina.

Słowa kluczowe: metoda Galerkina, dopasowanie impedancji o wysokim współczynniku dobroci, analiza obwodów nieliniowych, zbieranie energii o częstotliwościach radiowych

\section{Introduction}

The previous work of the authors has focused on high Q impedance matching for harvesting circuits. It could be shown in a former publication [3] that the use of a high Q resonator as an inductor in the matching network can lead to an improvement of the harvester efficiency.

This work focuses on the mathematical description of the output voltage in dependence on the input power for two example high Q and low Q harvester networks. Because of the nonlinear behavior of the diodes, which are used to rectify the harvested AC voltage, the dependence of the output voltage on the input power is also nonlinear. Because of this, the mathematical description of the harvester network leads to a nonlinear differential equation and a numerical method has to be used to approximate a solution. In this work, the Galerkin Method is used to find an approximated solution.

\section{Method}

The following harvester circuit is analyzed mathematically and by simulation.

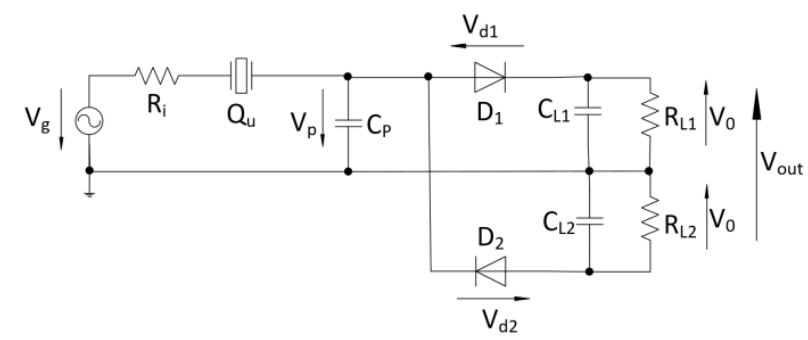

Fig. 1. RF energy harvesting circuit with Delon rectification (high $Q$ )

The circuit consists of a RF generator block, a high Q matching circuit in L-topology and a Delon rectifier. The RF generator block represents the equivalent circuit of the antenna of the harvester circuit and consists of a RF voltage source $V_{g}$ and a resistance $R_{g}$. The high Q matching circuit is comprised of a crystal resonator in the series leg and a capacitance in the parallel leg.

A crystal resonator is a resonant circuit with an equivalent circuit (see Fig. 2) consisting of a series motional resistance $\left(R_{I}\right)$, a series motional inductance $\left(L_{l}\right)$, a series motional capacitance $\left(C_{l}\right)$ and a shunt static capacitance $\left(C_{0}\right)$.

These parameters are also called Butterworth-van-Dyke (BVD) parameters. The three motional devices form a series resonance circuit and the static shunt capacitance forms a parallel resonance circuit together with $L_{l}$ and $C_{l}$.

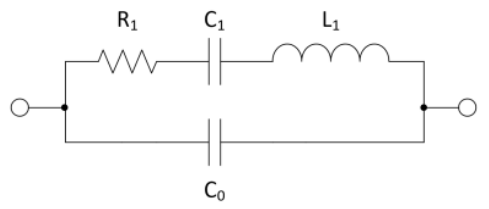

Fig. 2. Equivalent circuit of a resonator

The following figure shows the reactance diagram of a crystal resonator.

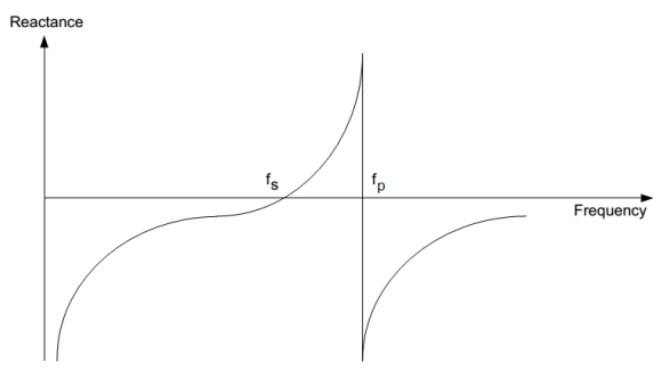

Fig. 3. Reactance diagram of a crystal resonator

The diagram in Fig. 3 shows that the resonator has an inductive behavior between the series resonance frequency $\left(f_{S}\right)$ and the parallel resonance frequency $\left(\mathrm{f}_{\mathrm{P}}\right)$. The series resonance frequency $\left(f_{S}\right)$ and the parallel resonance frequency $\left(f_{\mathrm{P}}\right)$ can be calculated as follows:

$$
\begin{gathered}
f_{S}=\frac{1}{2 \pi \sqrt{L_{1} C_{1}}} \\
f_{P}=\frac{1}{2 \pi \sqrt{L_{1} \frac{C_{1} C_{0}}{C_{1}+C_{0}}}}
\end{gathered}
$$

The rectifier includes two HSMS-282 diodes from Avago Technologies and the capacitors $C_{L 1}$ and $C_{L 2}$. The two resistors $R_{L 1}$ and $R_{L 2}$ represent the load of the harvester circuit. In the following, it is assumed that the load resistors and rectifier capacitors have the same values, that means $R_{L 1}=R_{L 2}=R_{L}$ and $C_{L 1}=C_{L 2}=C_{L}$.

The diodes can be modeled as varistors with a series resistor $R_{j}$ and a junction capacitance $C_{j}$. The following figure shows the equivalent circuit of the diode. 


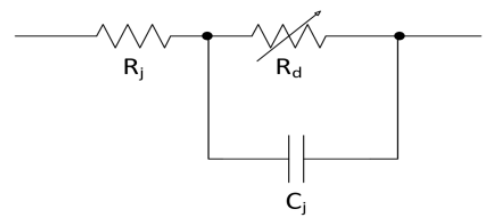

Fig. 4. Equivalent circuit of a diode [2]

The parameters of the HSMS-282 diode are:

- $\quad$ series resistance $R_{j=} 6 \Omega$,

- $\quad$ saturation current $I_{S}\left(T=T_{0=} 300 \mathrm{~K}\right)=22 \mathrm{nA}$

- $\quad$ junction capacitance $C_{j}\left(V_{D}=0 \mathrm{~V}\right)=0.7 \mathrm{pF}$,

- $\quad$ ideality factor $n=1.08$,

- metal-semiconductor energy gap $E_{G}=0.69 \mathrm{eV}$.

The current through the diode $I_{D}$ and the diode voltage $V_{D}$ have the following nonlinear relation:

$$
I_{D}=I_{S}(T) \cdot\left[\exp \left(\frac{q \cdot V_{D}}{n \cdot k \cdot T}\right)-1\right]
$$

where $I_{D}$ is the diode current, $V_{D}$ represents the diode voltage, $q=1.06 \cdot 10^{-19} \mathrm{C}$ denotes the elementary charge and $k=1.3806 \cdot 10^{-23} \mathrm{~J} / \mathrm{K}$ the Boltzmann constant.

Using the equivalent circuits of the diode and the resonator, the harvester circuit (see Fig. 1) can be designed as illustrated in Fig. 5.

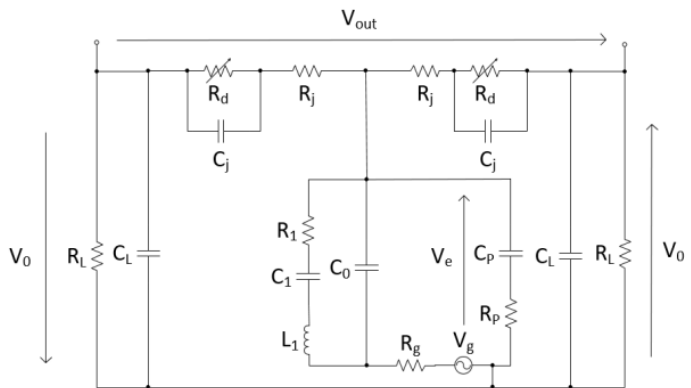

Fig. 5. Harvester circuit with the equivalent circuits of the resonator and the diodes

To simplify the analysis of the harvester network, the following partial network has firstly to be taken into account.

Fig. 6. Partial harvester network

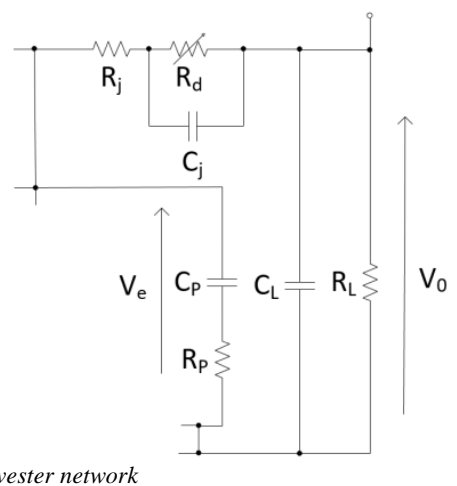

The straightforward analysis of the partial harvester network leads to the following nonlinear differential equation of second order:

$$
\begin{gathered}
I_{S}\left\{\exp \left[\alpha\left(v_{e}(t)+\beta v_{o}(t)+\gamma \frac{d v_{0}(t)}{d t}-v_{0}(t)\right)\right]-1\right\} \\
+C_{j} \frac{d v_{e}(t)}{d t}+\delta \frac{d v_{0}(t)}{d t}+\zeta \frac{d^{2} v_{0}(t)}{d t^{2}}-C_{j} \frac{d v_{0}(t)}{d t} \\
=\frac{v_{0}(t)}{R_{L}}+C_{L} \frac{d v_{0}(t)}{d t}
\end{gathered}
$$

where

$\alpha=\frac{q}{n \cdot k \cdot T}, \beta=\frac{R_{j}}{R_{L}}, \gamma=R_{j} C_{L}, \delta=\frac{R_{j} C_{j}}{R_{L}}$ and $\zeta=R_{j} C_{j} C_{L}$.

It is not possible to find a closed form of the solution for the differential equation. Because of this, a numerical method has to be used to find an approximated solution. A suitable numerical approximation method is the so called Galerkin method. To apply this method, the differential equation has to be brought into the form

$$
\xi\left[x, y, t, \frac{d}{d t}, \frac{d^{2}}{d t^{2}}\right] \equiv 0
$$

In equation (5) $\xi$ is a nonlinear operator. The exact solution cannot be determined, but is approximated by an assumed solution $\widetilde{\mathrm{y}}(\mathrm{t})$, which can be expressed with equation (6).

$$
\tilde{y}(t)=\sum_{k=1}^{N} a_{k} \phi_{k}(t)
$$

$\phi_{\mathrm{k}}(\mathrm{t})$ are $N$ linearly independent functions and $a_{k}$ are $N$ arbitrary constant coefficients. The assumed solution $\widetilde{y}(t)$ does not in general satisfy the differential equation exactly. Therefore, the expression obtained by substituting equation (6) into equation (5) is no longer equivalent to zero.

Instead

$$
\xi\left[x, \tilde{y}, t, \frac{d}{d t}, \frac{d^{2}}{d t^{2}}\right]=\varepsilon(t) \neq 0
$$

where $\varepsilon(t)$ is called the residual and is a measure of the deviance of the exact solution and therefore represents the incurred error. This error can be minimized if the residual satisfies the so called Ritz conditions:

$$
\begin{gathered}
\int_{t_{1}}^{t_{2}} \xi\left[x, \tilde{y}, t, \frac{d}{d t}, \frac{d^{2}}{d t^{2}}\right] \cdot \Phi_{k}(t) d t=0 \\
k=1,2, \ldots, N
\end{gathered}
$$

This conditions result in a system of $N$ algebraic equations with $N$ variables. To reduce this system of equations to one equation, the ripple of the output voltage has to be neglected, so that the assumed solution changes to

$$
\tilde{y}=V_{0}
$$

The input forcing function $x$ can be expressed as follows:

$$
x=v_{e}(t)=\hat{V}_{e} \cdot \cos (\omega t)
$$

Here $\hat{V}_{e}$ is the amplitude of the input function and the parameter $\omega$ represents the angular frequency of the RF source.

This simplification leads to only one Ritz condition:

$$
\int_{t_{1}}^{t_{2}} \xi\left[\hat{V}_{e} \cdot \cos (\omega t), V_{0}, t, \frac{d}{d t}, \frac{d^{2}}{d t^{2}}\right] d t=0
$$

If the assumed input and output functions, represented by the equations (10) and (9), are inserted into the differential equation (see equation (4)) the residual leads to the following formula:

$$
\varepsilon(t)=I_{S}\left\{\exp \left[\alpha\left(\hat{V}_{e} \cdot \cos (\omega t)+V_{0}(\beta-1)\right)\right]-1\right\}-C_{j} \cdot \hat{V}_{e} \cdot \sin (\omega t)-\frac{V_{0}}{R_{L}}
$$

Carrying out the integration specified in equation (11) and taking equation (12) into account, we get the following nonlinear relation between the input and output value:

$$
I_{0}\left(\alpha \cdot\left|\hat{V}_{e}\right|\right)=\left(1+\mu \cdot V_{0}\right) \cdot \exp \left(\alpha \cdot v \cdot V_{0}\right)
$$$$
\text { where } v=\frac{R_{j}+R_{L}}{R_{L}} \text { and } \mu=\frac{1}{R_{L} \cdot I_{S}} \text {. }
$$

To get the expression formulated in equation (13), the following formula has been used [1]:

$$
I_{0}(z)=\frac{1}{\pi} \int_{0}^{\pi} \exp [ \pm z \cdot \cos (\Theta)] d \Theta=\frac{1}{2 \pi} \int_{0}^{2 \pi} \exp [ \pm z \cdot \cos (\Theta)] d \Theta
$$

Here $I_{0}(z)$ is the zero-order modified Bessel function of first kind with argument $z$.

It has to be mentioned that the capacitances $C_{j}$ and $C_{L}$ do not appear in equation (13). This is the consequence of ignoring the ripple component of the output voltage $v_{0}(t)$.

The relation between the absolute value of the input amplitude $\left|\hat{V}_{e}\right|$ and the amplitude of the RF generator source voltage $\hat{V}_{g}$ can be calculated as follows:

$$
\left|\hat{V}_{e}\right|=\left|\frac{\hat{V}_{g} \cdot\left(\frac{1}{j \omega C_{p}}+R_{p}\right)}{R_{g}+Z_{Q}+\frac{1}{j \omega C_{p}}+R_{p}}\right|
$$


The impedance of the crystal resonator $Z_{Q}$ is:

$$
Z_{Q}=\frac{R_{1}+j \omega L_{1}+\frac{1}{j \omega C_{1}}}{\left(R_{1}+j \omega L_{1}+\frac{1}{j \omega C_{1}}\right) \cdot j \omega C_{0}+1}
$$

The relationship between $\hat{V}_{g}$ and the incident power $P_{i n}$, which is fed in at the antenna, can be expressed with the equation

$$
\hat{V}_{g}=\sqrt{8 \cdot R_{g} \cdot P_{i n}}
$$

The output voltage of the harvester system $V_{\text {out }}$ is twice as much as the output voltage of the partial network $V_{0}$ :

$$
V_{\text {out }}=2 \cdot V_{0} \rightarrow V_{0}=\frac{V_{\text {out }}}{2}
$$

\section{Results}

\subsection{High $Q$ matching}

The insertion of the formulas (15), (17) and (18) into formula (13) results into the following equation, which describes the nonlinear relation between the output voltage $V_{\text {out }}$ and the input power $P_{i n}$ :

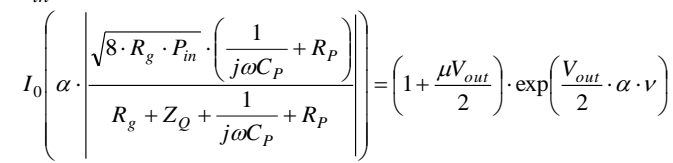

The equation (19) has been plotted (see Fig. 7) using the following parameters.

- Generator resistance $R_{g}=50 \Omega$,

- Equivalent series resistance of the matching capacitor $R_{P}=2.5 \Omega$

- Matching capacitor $C_{P}=9.3 \mathrm{pF}$,

- Series motional resistance $R_{I}=9.78 \Omega$,

- Series motional inductance $L_{l}=9.3 \mathrm{mH}$,

- Series motional capacitance $C_{l}=14.82 \mathrm{fF}$,

- Shunt static capacitance $C_{0}=3.3 \mathrm{pF}$,

- Operational frequency $f_{a}=13.562966967 \mathrm{MHz}$

- Load resistance $R_{L}=1 \mathrm{M} \Omega$.

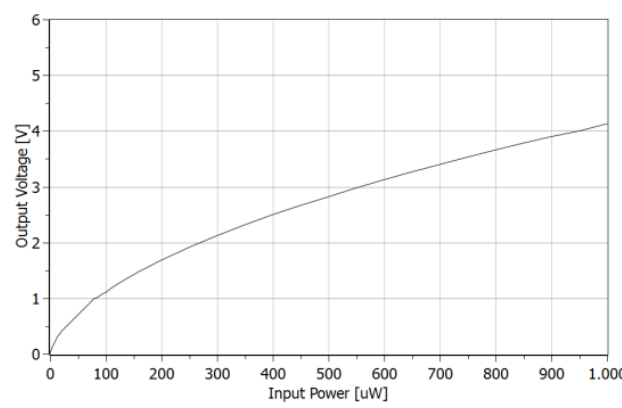

Fig. 7. Calculated output voltage versus input power (high $Q$ )

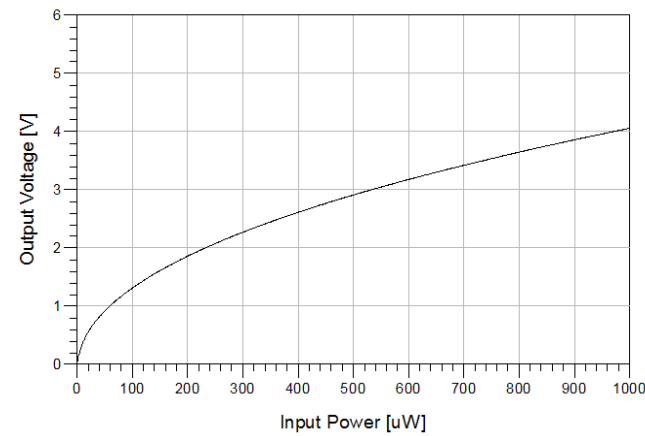

Fig. 8. Simulated output voltage versus input power (high $Q$ )

The output voltage in dependence on the input power has been simulated with Keysight Advanced Design System. The simulation result is shown in Fig. 8. The same parameters like in the calculations have been used.

The simulated and the calculated relation of the output voltage on the input power differs. The reasons for this are the simplifica- tions which are made at the calculations and that not all parameters of the harvester networks have been taken into account to reduce the complexity of the calculations. The simulation was performed with the so called harmonic balance method, which is a special version of the Galerkin method.

Fig. 9 shows the spectrum of the output voltage of the partial network $V_{0}$. The first harmonic has a magnitude of $-47.85 \mathrm{dBV}$ and the DC component has a magnitude of $-6.373 \mathrm{dBV}$, which leads to a ripple factor of $0.6 \%$. This shows that the neglection of the harmonics of the output voltage is suitable and does not influence the result significantly.

The value of the matching capacitor $C_{P}$ has been chosen so that the input port voltage reflection coefficient of the harvester network has a minimum between the series resonance frequency $(13.556 \mathrm{MHz})$ and the parallel resonance frequency $(13.586 \mathrm{MHz})$ of the crystal resonator at an input power of $10 \mu \mathrm{W}$. The resonant frequencies have been calculated with the formulas (1) and (2).

The following figure shows the input port voltage reflection coefficient versus the frequency at an input power of $10 \mu \mathrm{W}$.

The above figure shows that the input port voltage reflection coefficient has a value of $1.3 \%$ at the operational frequency $f_{a}$.

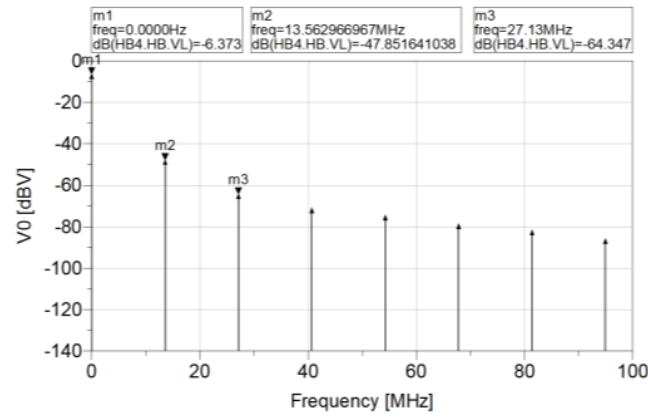

Fig. 9. Spectrum of the output voltage of the partial network $V_{0}$

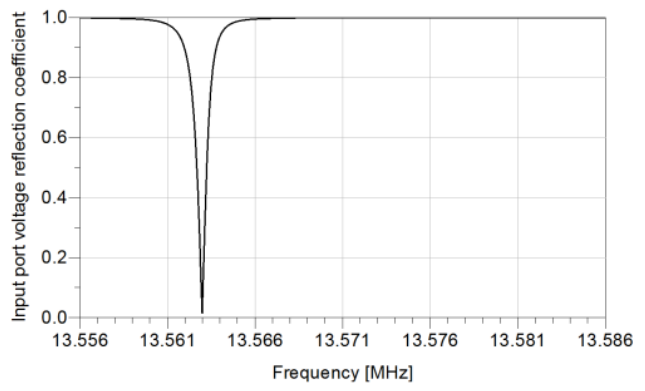

Fig. 10. Simulated voltage reflection coefficient versus frequency at an input power of $10 \mu \mathrm{W}$ (high $Q$ )

\subsection{Low $Q$ matching}

By substituting the crystal resonator with an off-the-shelf inductor, the high Q harvester network (see Fig. 1) is changed as indicated in Fig. 11.

Due to the substitution of the crystal by an inductor, the equation (19) changes as follows:

$$
I_{0}\left(\alpha \cdot\left|\frac{\sqrt{8 \cdot R_{g} \cdot P_{\text {in }}} \cdot\left(\frac{1}{j \omega C_{P}}+R_{P}\right)}{R_{g}+j \omega L_{S}+R_{S}+\frac{1}{j \omega C_{P}}+R_{P}}\right|\right)=\left(1+\frac{\mu V_{\text {out }}}{2}\right) \cdot \exp \left(\frac{V_{\text {out }}}{2} \cdot \alpha \cdot v\right)
$$

$\mathrm{L}_{\mathrm{S}}$ represents the inductance of the matching inductor and $R_{S}$ is the associated equivalent serial resistance. The component quality factor of the matching inductance, represented by the symbol $Q_{L}$, can be calculated with:

$$
Q_{L}=\frac{\omega L_{S}}{R_{S}}
$$

By optimizing with Advanced Design System with the goal to minimize the input port voltage reflection coefficient, the matching inductance results into a value of $8.6 \mu \mathrm{H}$ and the matching capacitor leads to a value of $14.8 \mathrm{pF}$. For the coil a component 
quality factor of 20 is assumed, which is a typical value for offthe-shelf inductors in the $\mu \mathrm{H}$-range. By using equation (21), the equivalent series resistance of the matching inductor leads to a value of $37 \Omega$.

The simulated input port voltage reflection coefficient versus the frequency at an input power of $10 \mu \mathrm{W}$ for the low $\mathrm{Q}$ matching circuit is shown in Fig. 12. The same parameters like in the high Q circuit have been used (except the matching component values) to ensure the comparability between the low $\mathrm{Q}$ and the high $\mathrm{Q}$ circuit.

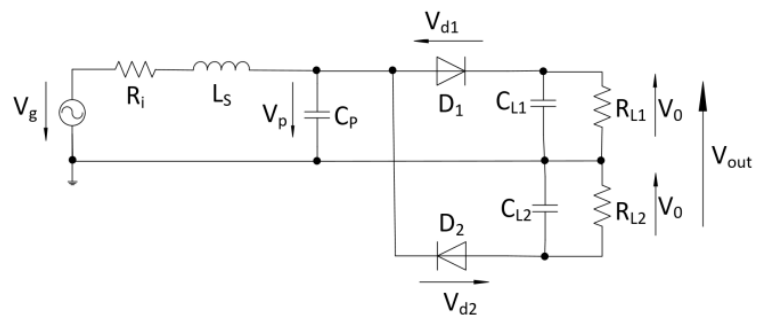

Fig. 11. RF energy harvesting circuit with Delon rectification (low $Q$ )

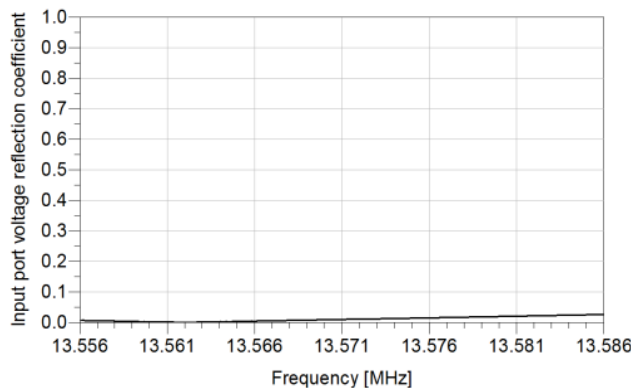

Fig. 12. Simulated voltage reflection coefficient versus frequency at an input power of $10 \mu \mathrm{W}$ (low $Q)$

The above figure shows that the input port voltage reflection coefficient has a value of $0.14 \%$ at the operational frequency and the value remains quite constant between $13.556 \mathrm{MHz}$ and $13.586 \mathrm{MHz}$.

The plot of the calculated output voltage of the low $\mathrm{Q}$ circuit in dependence on the input power, which is represented by equation (20), is visualized in Fig. 13.

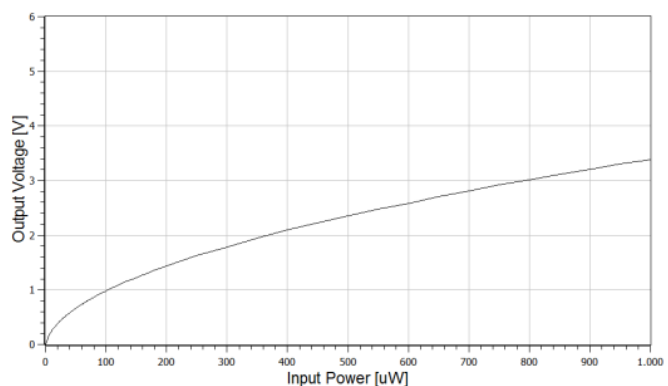

Fig. 13. Calculated output voltage versus input power (low $Q$ )

The output voltage in dependence on the input power has been simulated for the low $\mathrm{Q}$ circuit. The simulation result is shown in Fig. 14.

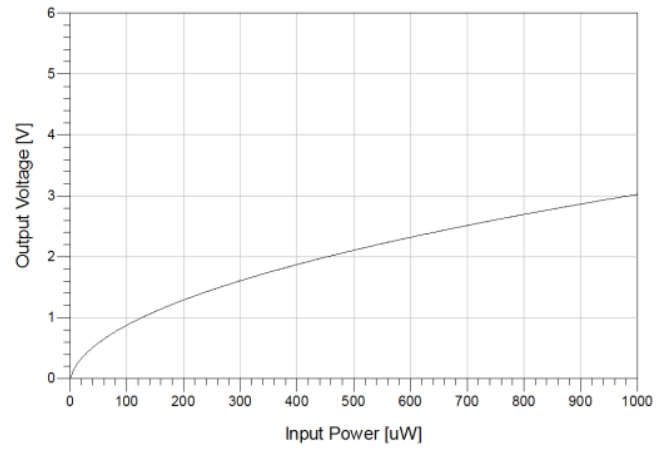

Fig. 14. Simulated output voltage versus input power (low $Q$ )
The difference of the output voltage between the high $\mathrm{Q}$ and the low $\mathrm{Q}$ circuit (represented by the parameter $\mathrm{dV}$ ) in dependence on the input power is plotted in Fig. 15.

The voltage difference increases with rising input power. At an input power of $1000 \mu \mathrm{W}$, the voltage difference has a value of $0.75 \mathrm{~V}$. This indicates that the benefit of the usage of a high $\mathrm{Q}$ resonator as inductor in the matching circuit gets higher with increasing input power.

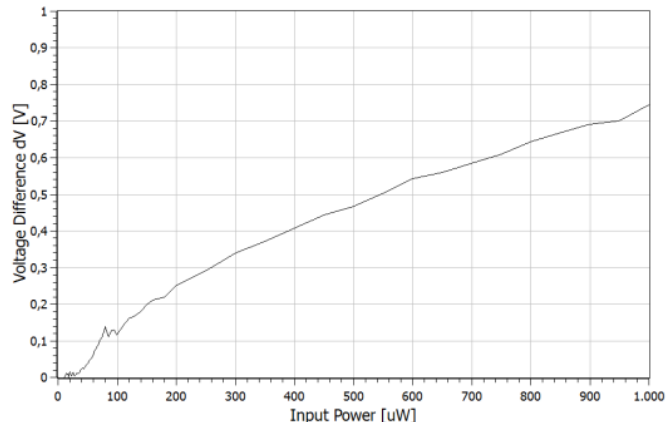

Fig. 15. Calculated voltage difference between high $Q$ and low $Q$ output voltag versus input powe

\section{Discussion}

In this paper, an approximated solution of a nonlinear differential equation of second order has been found by using the Galerkin method. The nonlinear relation between the output voltage of the harvester and the input power has been plotted and simulated with a harmonic balance simulation using Keysight Advanced Design System.

The same calculations and simulations have been carried out for the low $\mathrm{Q}$ version of the harvester network. The usage of a high $\mathrm{Q}$ resonator as an inductor in the matching circuit has led to an increase of the output voltage of the harvester.

The difference of the output voltage of the high $\mathrm{Q}$ and low $\mathrm{Q}$ harvester increases with rising input power.

In the future, this phenomenon has to be examined for different matching points, for example at lower load resistances and higher input powers.

\section{References}

[1] Abramowitz M., Stegun I.: Handbook of Mathematical Functions. Nationa Bureau of Standards, 1964

[2] Avago Technologies: HSMS-282x Surface Mount RF Schottky Barrier Diodes. Data Sheet, 2009

[3] Merz C., Kupris G.: High Q Impedance Matching for RF Energy Harvesting Applications. The 3rd IEEE International Symposium on Wireless Systems within the Conference on Intelligent Data Acquisition and Advanced Computing Systems, Offenburg, Germany, 2016.

\section{M.Sc. Merz Christian}

e-mail: christian.merz@th-deg.de

Mr. Merz has studied electrical engineering at the Deggendorf Institute of Technology. Currently he is a scientific researcher at the Deggendorf Institute of Technology in the field of energy harvesting, high Q impedance matching and nonlinear circuit analysis. He has published 11 papers about these topics.

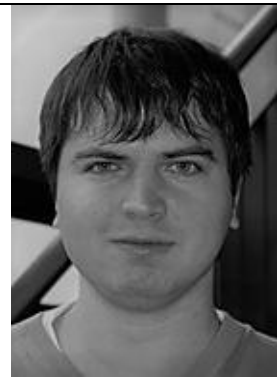

Prof. Dr.-Ing. Kupris Gerald e-mail: gerald.kupris@th-deg.de

Professor Kupris is the dean of the Faculty of Electrical Engineering, Media Technology and Computer Science at the Deggendorf Institute of Technology. He is researching on the field of internet of things, bluetooth low energy and energy harvesting.

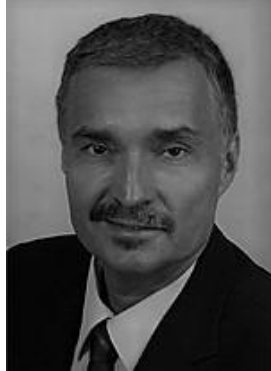

